\title{
MANIFESTAÇÕES PATOLÓGICAS E CONTROLE DE QUALIDADE NA MONTAGEM E FABRICAÇÃO DE ESTRUTURAS METÁLICAS
}

\section{Demonstrations in pathological steel structures and quality control in assembly and fabrication of steel structures}

\author{
Caio César Sacchi', Alex Sander Clemente de Souza
}

Recebido em 09 de maio de 2016; recebido para revisão em 05 de julho de 2016; aceito em 10 de agosto de 2016; disponível on-line em 31 de agosto de 2016.

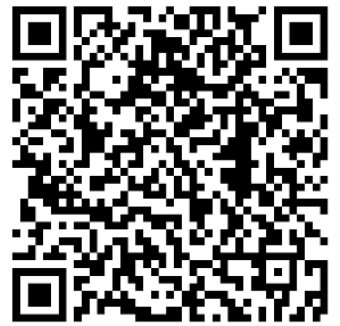

PALAVRAS CHAVE:

Estrutura metálica; Controle de qualidade; Pintura em estruturas metálicas;

Patologia em estruturas; Ensaios não destrutivos.

\section{KEYWORDS:}

Steel structure; Quality control; Painting in steel structures; Structures in pathology; Nondestructive testing.

\section{* Contato com os autores:}

${ }^{1}$ e-mail: caio.sacchi@gmail.com (C. C. Sacchi)

Mestrando do Departamento de Engenharia Civil da Universidade Federal de São Carlos - UFSCar.

2e-mail: alex@ufscar.br ( A. S. C. de Souza)

Professor Associado do Departamento de Engenharia Civil da Universidade Federal de São Carlos - UFSCar.
RESUMO: Este trabalho apresenta um estudo científico e tecnológico sobre o controle de qualidade na fabricação e montagem de estruturas metálicas, elaborado por meio da análise e interpretação de informações obtidas em levantamentos bibliográficos, visitas técnicas e entrevistas à empresas do setor, evidenciando o conhecimento da literatura existente. Sendo assim, serão abordadas as diversas etapas da fabricação e da montagem das estruturas metálicas, assim como ensaios utilizados para a garantia da qualidade na fabricação. A pesquisa tem como objetivos, definir critérios de inspeção durante a fabricação e a montagem das estruturas metálicas, para identificação prematura de manifestações patológicas, apresentar os principais sintomas patológicos encontradas em estruturas de aço, estabelecendo suas origens e causas, expor um fluxograma sobre o processo de produção de uma estrutura metálica, indicando os principais pontos de checagem de desempenho e, por fim, analisar algumas manifestações patológicas, indicando as falhas no processo de produção. Conclui-se que existem cuidados a serem observados para não cometer erros construtivos, facilmente evitáveis por meio de planejamento e fiscalização eficientes. O intuito do estudo é promover o intercâmbio dos resultados da pesquisa com o setor produtivo e colaborar na revisão e elaboração de normas.

ABSTRACT: This paper is a scientific and technological study about quality control in the fabrication and assembly of steel structures, developed through the analysis and interpretation of information obtained from literature surveys, technical visits and interviews with companies in the sector, highlighting the knowledge the existing literature. Therefore, they will discuss the processes for obtaining structural steel and its properties, the various stages of fabrication and assembly of steel structures, as well as tests used for quality assurance in fabrication. The survey aims to define inspection criteria for the fabrication and assembly of steel structures for early identification of pathological manifestations, present the main pathological symptoms found in steel structures, establishing its origins and causes, exposing a flow chart of the process production of a steel structure showing the main performance checkpoints and, finally, to analyze certain pathological events, indicating failures in the production process. It is concluded that there are precautions to be observed not to make constructive errors, easily preventable through efficient planning and supervision. The study's aim is to promote the exchange of research results to the productive sector and assist in the review and development of standards. 


\section{INTRODUÇÃO}

Projetar sistemas industrializados exige inovações tecnológicas e visão sistêmica da construção, constitui resolver integralmente aspectos como segurança, funcionalidade $e$ durabilidade. As falhas ou acidentes estruturais podem ter origens em qualquer uma das atividades inerentes ao processo de construção. Uma construção sistêmica está menos sujeita a falhas quando seu responsável possui uma visão global de todo o processo construtivo. Para um maior desenvolvimento na execução, deve-se propor um sistema de controle de qualidade nas diversas etapas de um projeto, com isso, poupar improvisos no canteiro de obras.

A implantação de um controle de qualidade no detalhamento, fabricação e montagem das estruturas garante a redução da necessidade de intervenções para corrigir falhas. Utilizar ensaios não destrutivos é uma ferramenta de grande importância na avaliação da integridade e do atual estado de uso das edificações (COSTA, 2012).

O interesse na realização desta pesquisa é justificado pela possibilidade de contribuição no âmbito científico, tecnológico, social e econômico, no sentido de comprovar a necessidade de estudos que contribuam para o aprimoramento da tecnologia e aplicação de sistemas estruturais metálicos na construção civil e finalmente, por se tratarem de assuntos de forte interesse prático, observando também uma contribuição para a formação mais racional e madura no que se refere à avaliação de desempenho estrutural e manifestações patológicas em estruturas metálicas.

\section{OBJETIVO}

O presente trabalho tem como objetivos os seguintes tópicos: (1) propor um plano de qualidade mínimo para a fabricação e montagem de estruturas metálicas, definindo critérios para diferentes padrões de estruturas; (2) definir níveis de inspeção durante a fabricação e a montagem de estrutura metálica, para identificação prematura de manifestações patológicas; (3) fazer um levantamento e análise das principais manifestações patológicas estruturais encontradas em construções de aço, estabelecendo suas origens e causas.

Desse modo, busca-se apresentar uma visão geral da construção em estruturas metálicas com foco na gestão do controle de qualidade, desde o projeto, fabricação e finalmente a montagem.

Serão expostas algumas manifestações patológicas que se apresentam frequentemente em estruturas metálicas, devido à falta de controle de qualidade nas etapas do processo e na manutenção da estrutura.

\section{METODOLOGIA}

Este trabalho tem características que o classificam como uma pesquisa exploratóriadescritiva, afim de buscar e desenvolver conceitos sobre um plano de qualidade no projeto, fabricação e montagem de estruturas metálicas.

Foram feitos diversos levantamentos bibliográficos, além de visitas técnica e entrevistas em empresas do setor. Neste trabalho, as empresas visitadas serão nominadas como A e B. Estas empresas são dedicadas ao cálculo, projeto, fabricação e montagem de estruturas metálicas.

Com base literária foi utilizado artigos técnicos, dissertações e teses buscados em programas clássicos de pós-graduação do Brasil, na área de estruturas metálicas, como a Universidade Federal de Ouro Preto, Universidade Federal de Minas Gerais e a Escola Politécnica da Universidade de São Paulo, além de normas técnicas nacionais e internacionais, livros de autores renomados, como Bellei, manuais técnicos, visitas técnicas e entrevista à profissionais da área. Desse modo, analisou-se as principais etapas para o controle de qualidade, além das principais manifestações patológicas que ocorrem por negligência ou inexistência de controle de qualidade.

Por fim, serão apresentadas as principais origens de manifestação patológicas motivadas por falhas no controle de qualidade em alguma etapa da construção. Manifestações estas, levantadas em visitas técnicas realizadas em empresas de projeto, fabricação e montagem de estruturas metálicas. 
Com isso, aprofunda-se o conhecimento em relação aos procedimentos para a concepção de estruturas metálicas, com controle de qualidade da gestão das principais fases do processo.

\section{PATOLOGIA DAS ESTRUTURAS METÁLICAS}

No Brasil, as construções desde pequeno porte até as de grande porte, como pontes, viadutos, túneis, obras hidráulicas, construções residenciais e comerciais, sofrem pela ação do clima. Elevados gradientes de temperatura, muitas vezes no mesmo dia, grandes volumes de chuvas, poluições e ambientes de grande agressividade contribuem para o surgimento de manifestações patológicas que estão associadas com uma ou mais formas de deterioração. A seguir é apresentado o Quadro 1 com as principais origens de manifestações patológicas na construção civil em geral.

As anomalias em estruturas metálicas também são, na grande maioria, resultantes de falhas de projetos, erros na fabricação e montagem das estruturas causadas por negligência ou inexistência de controle de qualidade ou então da falta de manutenção.

Segundo Pravia e Betinelli (2016) as manifestações patológicas mais comuns em estruturas de aço podem ser definidas em seis tipos principais, conforme mostrados no Quadro 2.

QUADRO 1: Principais origens de manifestações patológicas na construção civil em geral.

\begin{tabular}{|c|c|}
\hline \multicolumn{2}{|c|}{ Fontes de anomalias na construção } \\
\hline Causa & Porcentagem \\
\hline Projeto & $42,00 \%$ \\
\hline Execução & $28,40 \%$ \\
\hline Materiais & $14,50 \%$ \\
\hline Uso & $9,50 \%$ \\
\hline Vários & $5,60 \%$ \\
\hline
\end{tabular}

QUADRO 2: As manifestações patológicas mais comuns e as principais causas.

\begin{tabular}{|l|l|}
\hline \multicolumn{1}{|c|}{ Manifestações patológicas no aço } & \multicolumn{1}{|c|}{ Principais causas } \\
\hline Corrosão localizada & $\begin{array}{l}\text { Causada por deficiência de drenagem das águas } \\
\text { pluviais e deficiências de detalhes construtivos, } \\
\text { permitindo o acúmulo de umidade e de agentes } \\
\text { agressivos. }\end{array}$ \\
\hline Corrosão generalizada & $\begin{array}{l}\text { Causada pela ausência de proteção contra o processo } \\
\text { de corrosão. }\end{array}$ \\
\hline Deformações excessivas & $\begin{array}{l}\text { Causadas por sobrecargas ou efeitos térmicos não } \\
\text { previstos no projeto original, ou ainda, deficiências na } \\
\text { disposição de travejamentos. }\end{array}$ \\
\hline Flambagem local ou global & $\begin{array}{l}\text { Causadas pelo uso de modelos estruturais incorretos } \\
\text { para verificação da estabilidade, ou deficiências no } \\
\text { enrijecimento local de chapas, ou efeitos de } \\
\text { imperfeições geométricas não consideradas no } \\
\text { projeto e cálculo. }\end{array}$ \\
\hline Fratura e propagação de fraturas & $\begin{array}{l}\text { Falhas estas iniciadas por concentração de tensões, } \\
\text { devido a detalhes de projeto inadequados, defeitos de } \\
\text { solda, ou variações de tensão não previstas no } \\
\text { projeto. }\end{array}$ \\
\hline
\end{tabular}


De maneira geral, os agentes agressivos que afetam o comportamento das construções durante o seu tempo de vida útil são:

- ações ambientais, como elevada umidade, respingos de marés, etc;

- agentes externos agressivos: águas contaminadas, terrenos com solo contaminado, gases nocivos, produtos químicos, etc;

- causas naturais ligadas ao envelhecimento dos materiais componentes das estruturas (por exemplo, corrosão);

A corrosão é um tipo de deterioração que pode ser facilmente encontrada em obras metálicas e se caracteriza como um fenômeno patológico de maior conhecimento público. O aço oxida quando em contato com gases nocivos ou umidade, necessitando por isso de cuidados para prolongar sua durabilidade.

\subsection{FALHAS EM PROJETOS}

A vida útil de uma estrutura nasce no projeto e se consolida na execução, mas os conceitos do projeto devem chegar até a conclusão da execução. Em cada uma das diretrizes há vários desafios a serem vencidos, como o de entender que projetar é fazer a gestão do desempenho da estrutura ao longo do tempo, controlando o processo de perda do desempenho e prevenindo

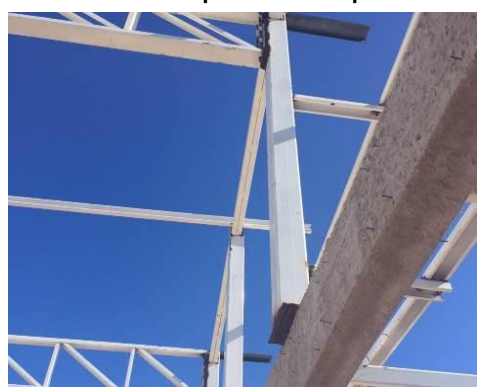

[a]

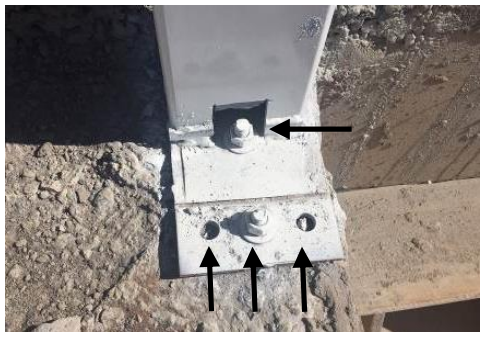

[c] falhas durante um período que justifique os recursos investidos.

Segundo empresas do setor entrevistadas pelo autor, no geral, a predisposição da construção para apresentar problemas patológicos nas estruturas de aço, ou de uma de suas partes são resultantes da má concepção de projeto, erros de cálculo, má compatibilidade dos projetos, no sistema de montagem, na escolha inadequada dos perfilados, definição equivocada das espessuras das chapas e do uso de tipos de aço com resistências diferentes das consideradas no projeto. As empresas relataram ainda que, as falhas em estruturas metálicas ocorrem também por falta de um plano de controle de qualidade nas etapas de projeto, fabricação e montagem. Tais problemas, muitas vezes são resolvidos de maneira inadequada e ineficiente.

De extrema importância, é a integração entre as áreas de projeto, fabricação e montagem, onde deverão ser discutidas as soluções de projetos e as características das peças fabricadas, de tal sorte a se evitar na montagem a não disponibilidade de equipamentos, custo excessivo, incompatibilidade da sequência construtiva, alteração no esquema estático e falta de segurança do trabalho. (RAAD JÚNIOR, 1999).

As fotos da Figura 1 apresentam situações de falhas devido a falhas de projeto.

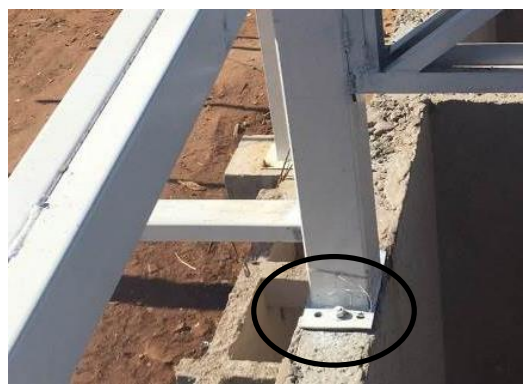

[b]

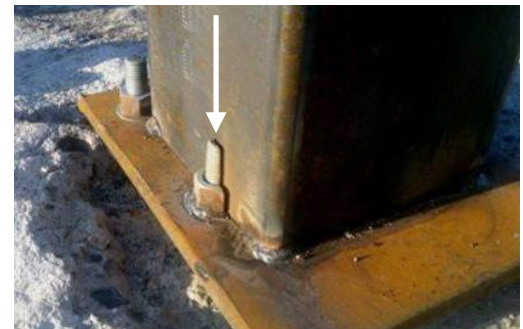

[d]

FIGURA 1: Situação de falhas na estrutura metálica devido a incompatibilidade de projeto, sendo: [a] falha na compatibilidade entre projeto de estruturas metálicas e o de concreto armado; [b] erro de compatibilidade de projetos - o alinhamento dos furos encontra as armaduras da estrutura de concreto armado; [c] aberturas imprevistas; [d] erro no gabarito de furação.

FONTE: Autoria própria (Obra da Unidade de Pronto Atendimento de São Carlos - SP, 2016). 
Nas fotos da Figura 1 são apresentadas falhas como incompatibilidade dos projetos de estruturas metálicas com os de estruturas em concreto armado, falhas no gabarito de furação, além de furos não previstos em projeto, realizados no momento da montagem. Tais furos tiveram a necessidade de serem executados na montagem devido a pequena distância deixada entre o furo e a borda da estrutura de concreto.

Segundo Bauermann (2002), no desenvolvimento dos projetos deve-se levar em conta todo o processo de produção, e no caso das construções metálicas, incluem-se a fabricação de componentes industrializados, o transporte e a montagem dos mesmos, resultando em um plano de atividade que deve ser desenvolvida pelos especialistas envolvidos no projeto.

As estruturas metálicas requerem cuidados no momento da concepção do projeto e caderno de encargos (detalhamento das ligações e tratamentos de prevenção). Falhas no seu cumprimento originam problemas frequentes, como corrosão dos elementos resistentes e uma menor segurança à incêndios. Outro grande problema enfrentado em obra é a presença de locais inacessíveis para o aperto dos parafusos. A seguir é apresentado o Quadro 3 com as principais causas que originam anomalias em estruturas metálicas provenientes de falhas em projeto.

Em projetos, devem ser previstos espaços para facilitar a execução da montagem. Para realizar uma ligação, é preciso colocar o parafuso no furo, colocar a anilha e a porca no outro lado e ainda ter espaço para a movimentação da chave de aperto e do braço do montador. No caso da Figura 2 é possível notar a falta de previsão de espaço para a parafusagem.

\begin{tabular}{|c|c|}
\hline \multicolumn{2}{|c|}{ QUADRO 3: Causas de falhas em projetos. } \\
\hline Causa & Porcentagem \\
\hline Detalhamento deficiente & $59,00 \%$ \\
\hline Concepção geral & $18,00 \%$ \\
\hline Erros de cálculo & $13,00 \%$ \\
\hline Materiais inadequados & $10,00 \%$ \\
\hline
\end{tabular}

FONTE: BUREAU SECURITAS (1979).

Na Figura 2 e na parte destacada, podem ser vistas dobras nos perfis para colocação dos parafusos; esta prática pode ser danosa à estrutura.

Pode acarretar basicamente dois problemas: falta de resistência nos parafusos, se estes têm áreas inferiores às calculadas; susceptibilidade de escoamento ou rotura na região dos furos, se esses tiveram de ser ampliados por divergências no projeto.

Nesse caso, existe, portanto, a necessidade de recalcular a ligação para verificar a estabilidade desejada. Esses erros ocorrem, muitas vezes, devido à não observância das diferentes fases de um projeto. Muitas vezes, o projetista realiza alterações e esquece-se de passar a informação para todos os níveis do projeto, chegando à obra um modelo de versão anterior e ao fabricante o modelo atualizado.

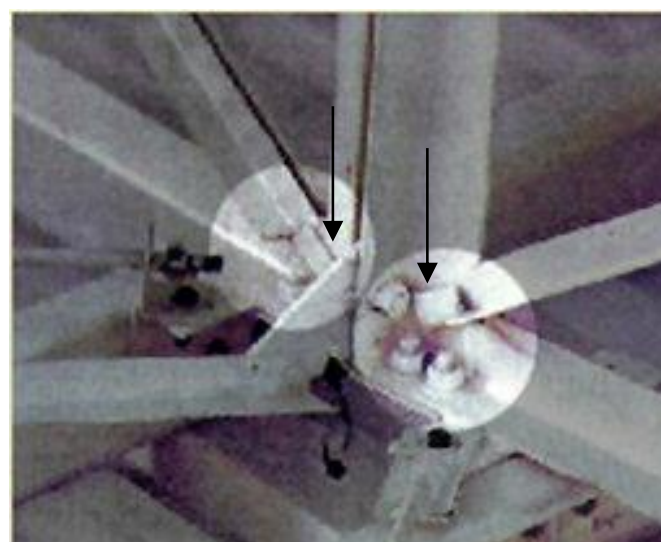

FIGURA 2: Adaptação na montagem por falta de previsibilidade de espaço para os parafusos. FONTE: NETTO (2010). 


\subsection{FALHAS NA FABRICAÇÃO}

O trabalho realizado dentro de uma fábrica de estruturas metálicas está sujeito a diversos métodos de inspeção. O fabricante deve estabelecer métodos de controle de qualidade, para garantir que todo o trabalho seja executado de acordo com as exigências. A inspeção é executada por funcionário qualificado e certificado para exercer a função e atuam em todas as fases do processo de fabricação. Na maioria das obras o cliente pode contratar inspetores para atuarem junto ao fabricante.

Além dos procedimentos de controle de qualidade do fabricante, o material e a qualidade do serviço devem ficar permanentemente sujeitos à inspeção por parte de profissionais qualificados, representantes do proprietário da obra.

Na Figura 3 é apresentado um corte da seç̧ão transversal de uma junta soldada de topo com penetração total (JTPT) contendo uma indicação de trinca longitudinal na superficial na solda.

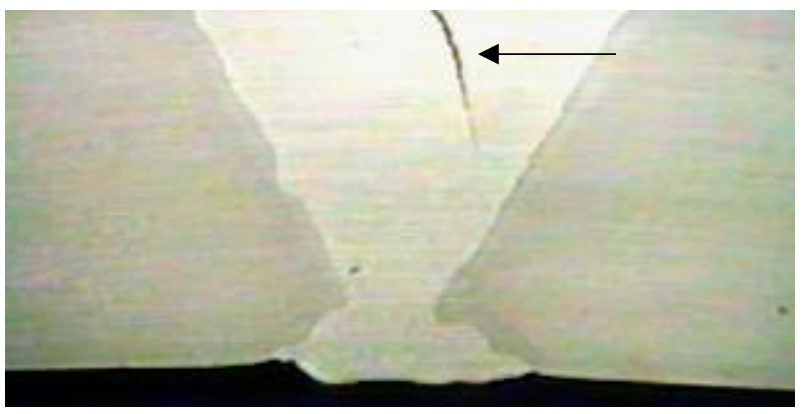

FIGURA 3: Junta soldada apresentando trinca longitudinal na superficial na solda. FONTE: ANDREUCCI (2014).

Todas as soldas devem ser totalmente inspecionadas visualmente e devem atender os critérios de aceitação da Tabela 6.1 da AWS D1-1, (2010) e estarem livres de trincas, sobreposições e descontinuidades.

A seguir são apresentados na Figura 4 alguns exemplos de falhas na soldagem que podem ser inspecionadas visualmente.

\subsection{FALHAS NA PINTURA}

A pintura industrial é uma técnica de proteção anticorrosiva existente, ela tem por finalidade aplicação de revestimentos anticorrosivos através da pintura, e com certeza é uma das técnicas mais utilizadas para proteção do aço. Os defeitos encontrados nas pinturas são, em sua maioria, identificados visualmente. A seguir, no Quadro 4, serão apresentados os defeitos mais comuns encontrados na prática, suas formas de apresentação, eventuais causas e possíveis correções.

\subsection{FALHAS NA MONTAGEM}

Devido às condições particulares de cada obra, como acessibilidade, topografia local, disponibilidade de canteiro, tipo de estrutura, entre outras, a montagem estará sujeita a desafios específicos e próprios de cada empreendimento. Sendo assim, deve ser elaborado um plano de montagem que contempla desenhos e diagramas de montagem, desenhos e constituintes dos subconjuntos da estrutura (treliças), programação de embarque, lista de expedição (define composição de cada subconjunto e modo a ser enviado para obra), cronograma e prazo final, no intuito de orientar todo o processo relacionado aos aspectos específicos de montagem, tipo de estrutura e concepções de fabricação. (RAAD JUNIOR, 1999).

Na Figura 5 são expostas algumas fotos que revelam falhas na montagem de esturras metálicas.

As fotos da Figura 5 apresentam falhas no momento da montagem, como erro de locação da estrutura. $O$ eixo do pilar da estrutura metálica não coincidiu com o eixo do bloco de fundação, com isso, foi realizado, de maneira inadequada e ineficiente, um prolongamento no bloco de concreto, porém, sequer chegou-se a concretar até a cota inicial do bloco, deixando um volume de concreto suspenso e sem função estrutural. Outras falhas apresentadas correspondem a emendas soldadas no canteiro de obras, o que prejudica o controle de qualidade dessas ligações e demonstram a falta de planejamento na montagem, e parafusos entortados por razão de imprecisão e falta de capacitação da mão de obra. 


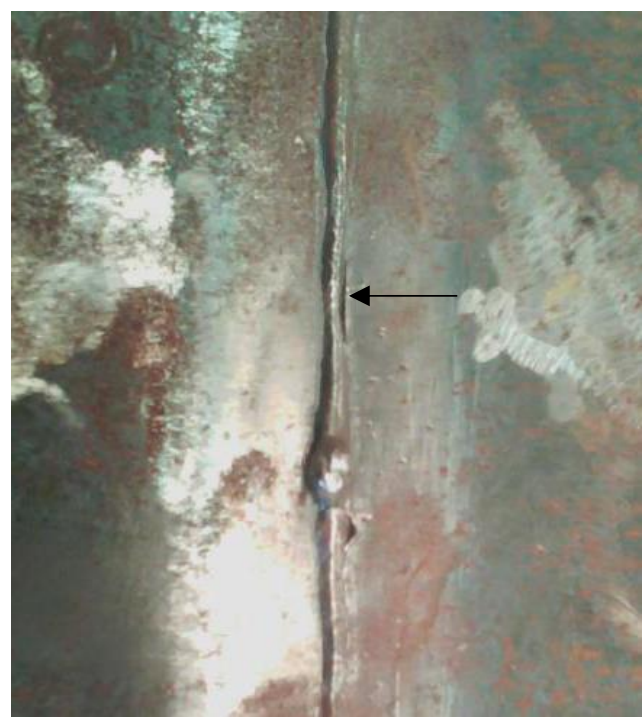

[a]

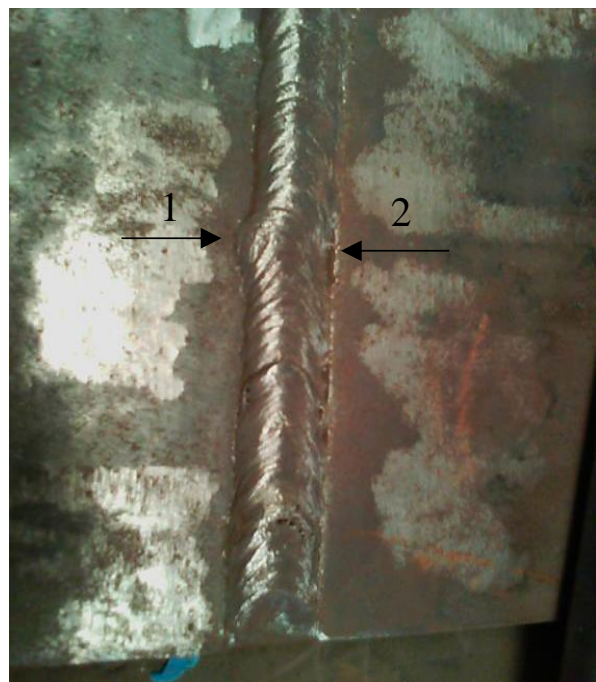

[c]

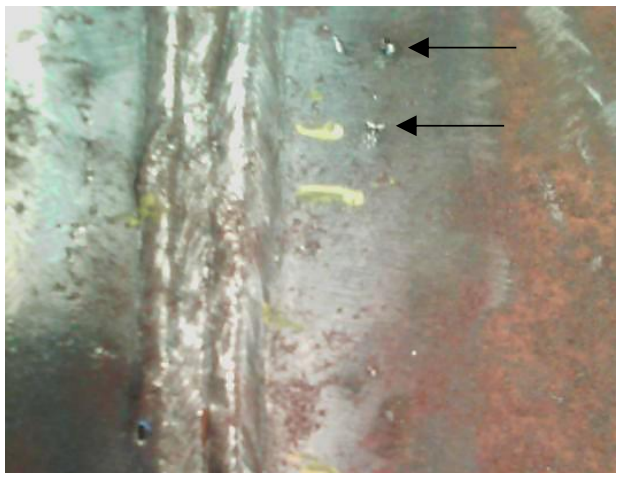

[e]

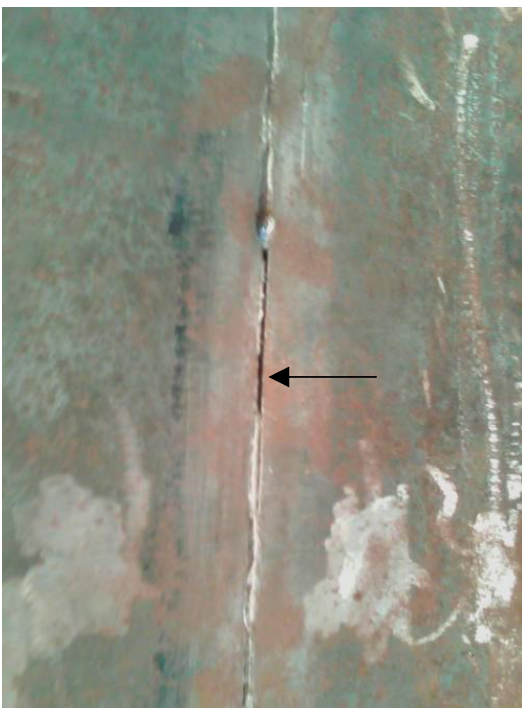

[b]

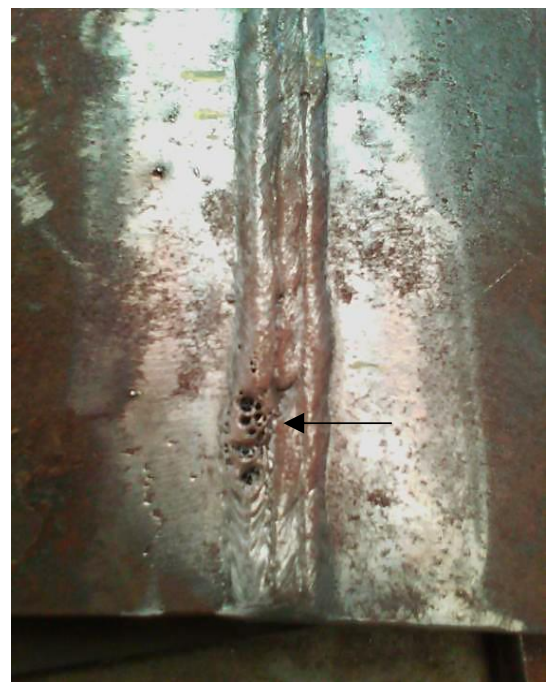

[d]

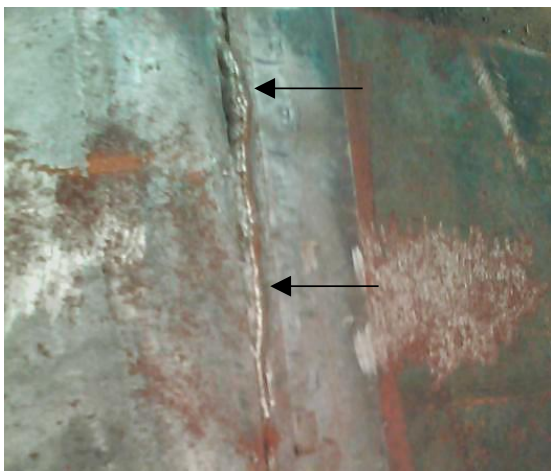

[f]

FIGURA 4: falhas na soldagem que podem ser inspecionadas visualmente. [a] falta de Fusão na soldagem. [b] falta de penetração. [c] 1-Sobreposição/ 2-Mordedura. [d] Porosidade. [e] Respingos. [f] Penetreção excessiva.

FONTE: NETTO (2010). 
QUADRO 4: Falhas e defeitos nas pinturas - causas e soluções.

\begin{tabular}{|c|c|c|}
\hline $\begin{array}{c}\text { Descrição dos tipos de falhas ou } \\
\text { defeitos }\end{array}$ & Causas & Correções \\
\hline $\begin{array}{l}\text { Impregnação (lixa): } \\
\text { Superfície da tinta apresenta-se } \\
\text { áspera como lixa. }\end{array}$ & $\begin{array}{l}\text { Abrasivos e poeiras levados pelo vento para } \\
\text { a tinta ainda úmida. } \\
\text { Pintura sobre superfícies contaminadas com } \\
\text { abrasivos e poeira. } \\
\text { Aplicação de tintas com rolo ou trincha } \\
\text { contaminados com pelos, areia, poeira ou } \\
\text { abrasivos. }\end{array}$ & $\begin{array}{l}\text { Proteger a área a ser pintada. } \\
\text { Retirar a tinta ainda úmida com panos } \\
\text { umedecidos em solventes. } \\
\text { Lixar a pintura contaminada e aplicar } \\
\text { nova demão. }\end{array}$ \\
\hline $\begin{array}{l}\text { Poros (porosidade): } \\
\text { A película de tinta apresenta } \\
\text { descontinuidades invisíveis a olho } \\
\text { nu ou não. }\end{array}$ & $\begin{array}{l}\text { Superfície contaminada. } \\
\text { Retenção de solventes ou ar no filme de tinta. } \\
\text { Atomização deficiente. } \\
\text { Temperatura do substrato muito alta. } \\
\text { Água no ar de atomização da pistola. }\end{array}$ & $\begin{array}{l}\text { Lixar a superfície e aplicar nova demão, } \\
\text { ou retirar toda a pintura e fazer nova } \\
\text { aplicação. }\end{array}$ \\
\hline $\begin{array}{l}\text { Pele ou casca de laranja: } \\
\text { A pintura apresenta-se rugosa } \\
\text { semelhante a uma casca de } \\
\text { laranja. }\end{array}$ & $\begin{array}{l}\text { Ocorre nas aplicações com pistola devido: } \\
\text { - à proximidade da superfície. } \\
\text { - à pressão baixa na pistola. } \\
\text { - à um solvente muito volátil } \\
\text { - à tinta muito viscosa. } \\
\text { - à umidade no solvente. } \\
\text { - à um bico inadequado. }\end{array}$ & $\begin{array}{l}\text { Ajustar as condições de aplicação. } \\
\text { Lixar e aplicar novas demãos. }\end{array}$ \\
\hline $\begin{array}{l}\text { Pulverização seca } \\
\text { (over spray): } \\
\text { A superfície da tinta apresenta um } \\
\text { aspecto fosco e áspero, porém } \\
\text { sem o desprendimento do pó. }\end{array}$ & $\begin{array}{l}\text { Solvente muito volátil. } \\
\text { Pistola muito distante da superfície ou com } \\
\text { pressão excessiva. } \\
\text { Temperatura ambiente muito elevada. }\end{array}$ & $\begin{array}{l}\text { Aplicar um pano umedecido com } \\
\text { solvente antes da secagem da tinta. } \\
\text { Após a secagem, lixar e aplicar nova } \\
\text { demão, ajustando a distância da pistola } \\
\text { à superfície e/ou utilizando um solvente } \\
\text { menos volátil. }\end{array}$ \\
\hline $\begin{array}{l}\text { Empolamento (bolhas): } \\
\text { A película de tinta apresenta-se } \\
\text { com saliências semiesféricas que } \\
\text { variam de tamanho e intensidade. }\end{array}$ & $\begin{array}{l}\text { Retenção de solventes. Processo corrosivo } \\
\text { acelerado. Efeito de eletrosmose. } \\
\text { Contaminação do ar e/ou dos equipamentos } \\
\text { de aplicação com sal, óleo, água e outros. } \\
\text { Incompatibilidade entre demãos de tintas. } \\
\text { Umidade relativa do ar elevada. Superfície } \\
\text { fria. }\end{array}$ & $\begin{array}{l}\text { Após secar, lixar as partes afetadas, } \\
\text { preparar a superfície e repintar } \\
\text { conforme a especificação técnica. } \\
\text { A depender da extensão do problema, } \\
\text { deve-se lixar e aplicar novas demãos. }\end{array}$ \\
\hline $\begin{array}{l}\text { Enrugamento: } \\
\text { A película de tinta apresenta-se } \\
\text { irregular, com encolhimento e/ou } \\
\text { ondulação da película. }\end{array}$ & $\begin{array}{l}\text { Espessura da película muito alta. Solventes } \\
\text { muito voláteis. Superfície fria. Não } \\
\text { atendimento dos intervalos entre demãos. }\end{array}$ & $\begin{array}{l}\text { Após secar, lixar as partes afetadas, } \\
\text { preparar a superfície e repintar } \\
\text { conforme a especificação técnica. A } \\
\text { depender da extensão do problema, } \\
\text { deve-se remover ou lixar a pintura a } \\
\text { aplicar novas demãos. }\end{array}$ \\
\hline $\begin{array}{l}\text { Sangramento: } \\
\text { A película apresenta-se } \\
\text { manchada pelo afloramento de } \\
\text { substâncias ou pigmento da cor } \\
\text { da demão que está abaixo, } \\
\text { devido à solubilidade da demão } \\
\text { inferior. }\end{array}$ & $\begin{array}{l}\text { Cores claras sobre cores escuras, } \\
\text { principalmente sobre o vermelho ou } \\
\text { marrom. O solvente do novo acabamento } \\
\text { dissolve a tinta antiga. A ação de solventes } \\
\text { fortes da tinta de acabamento provoca a } \\
\text { dissolução da tinta de fundo, manchando o } \\
\text { acabamento. Aplicação de tintas sobre tintas } \\
\text { à base de alcatrão. }\end{array}$ & $\begin{array}{l}\text { Dar uma demão de selagem. } \\
\text { Consultar o fabricante quanto a } \\
\text { recomendação de produtos }\end{array}$ \\
\hline $\begin{array}{l}\text { Oxidação Precoce: } \\
\text { A superfície pintada apresenta-se } \\
\text { com pontos de corrosão logo } \\
\text { após a aplicação da primeira ou } \\
\text { das primeiras demãos. }\end{array}$ & $\begin{array}{l}\text { Rugosidade excessiva (picos expostos). } \\
\text { Película muito fina em meios muito } \\
\text { agressivos. }\end{array}$ & $\begin{array}{l}\text { Controlar a rugosidade. } \\
\text { Aplicar demãos mais espessas em } \\
\text { ambientes mais agressivos. Diminuir, } \\
\text { dentro dos limites, os intervalos entre } \\
\text { demãos para reduzir os riscos de } \\
\text { corrosão precoce. }\end{array}$ \\
\hline
\end{tabular}




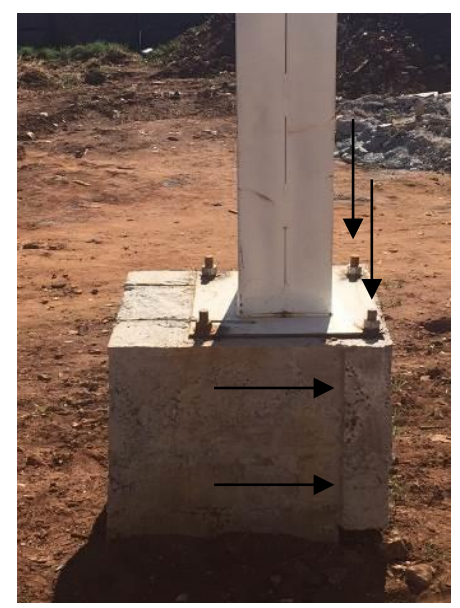

[a]

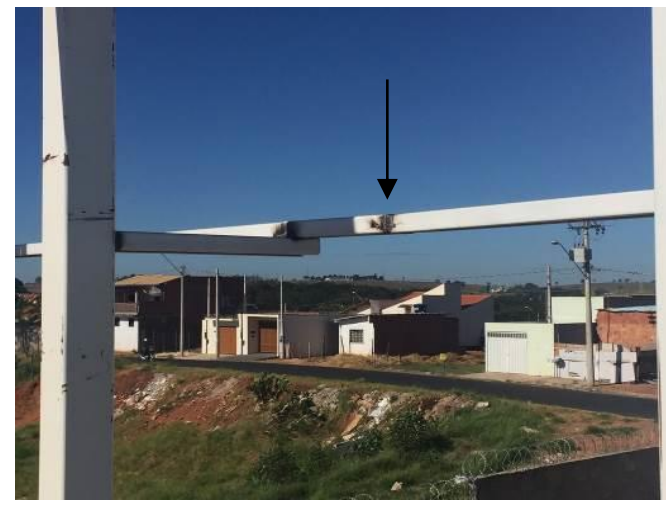

[c]

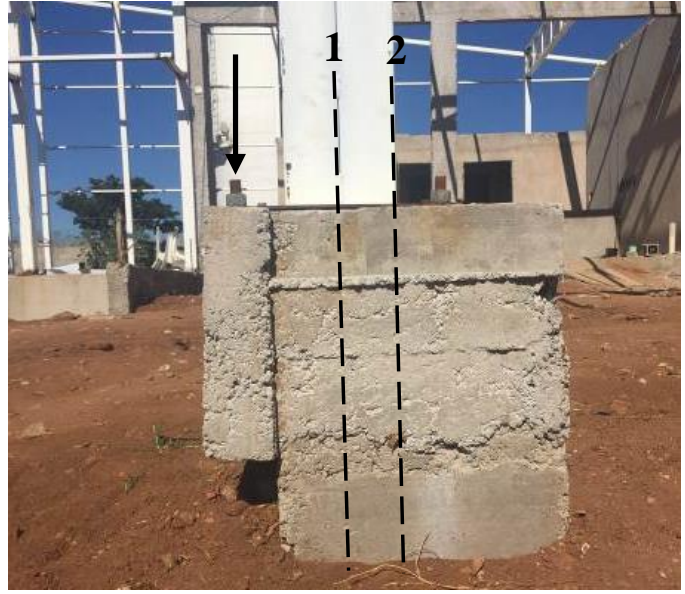

[b]

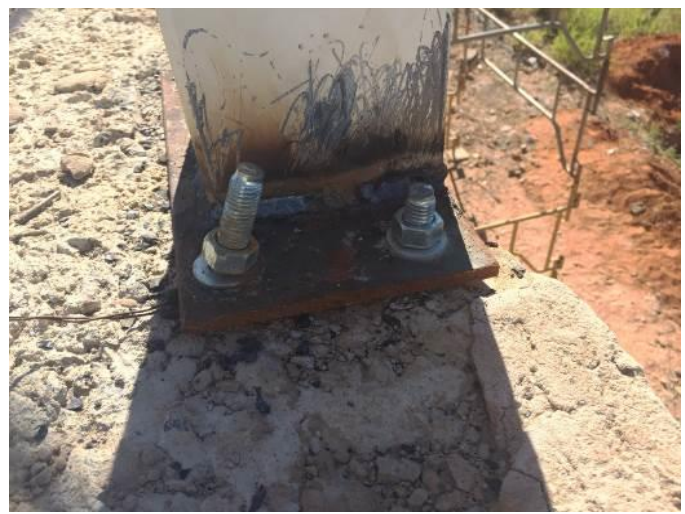

[d]

FIGURA 5: Falhas na montagem de estruturas metálicas. [a] Pilar desalinhado com o bloco de fundação; [b] 1 - Eixo do pilar, 2 - Eixo do Bloco de fundação; [c] peça emendada por solda no canteiro de obras; [d] parafuso entortado. FONTE: Autoria própria (Obra da Unidade de Pronto Atendimento de São Carlos - SP, 2016).

\section{CONTROLE DE QUALIDADE NA FABRICAÇÃODE ESTRUTURAS METÁLICAS}

O controle de qualidade reúne todas as atividades que visam a prevenção de falhas de projeto, fabricação e montagem, não se restringindo somente à função de inspeção. Além da verificação das matérias-primas, do produto em fabricação, da montagem, das ferramentas e dos calibradores, inclui a investigação das causas dos defeitos, a escolha dos métodos e dos planos de inspeção, a análise dos dados relativos às perdas e a determinação do nível de qualidade desejado no mercado.

\subsection{ENSAIOS NÃO DESTRUTIVOS EM LIGAÇÕES SOLDADAS}

Os ensaios não destrutivos são utilizados para determinar características, propriedades (ensaios físico-químicos), dimensões (ensaios metrológicos) ou comportamento de peças ou equipamentos (ensaios funcionais). A inspeção visual é qualificada pela norma da Petrobras N - 1597 REV. D - Ensaio não - destrutivo visual. $O$ ensaio de Líquido penetrante é normatizado pela norma Petrobras N - 1596 VER. H - Ensaio não destrutivo - Líquido penetrante. A inspeção por partículas magnéticas é qualificada pela norma da Petrobras N-1598 REV. E - ensaio não - destrutivo partículas magnéticas. O ensaio radiográfico é qualificado pela norma Petrobras. N - 1595 REV. G - Ensaio não - destrutivo - Radiografia. A inspeção por Ultrassom é qualificada pela norma Petrobras N-1594 REV.F - Ensaio não - destrutivo - Ultrassom.

No Quadro 5 são apresentados os ensaios não destrutivos mais comuns realizados em estruturas metálicas, com suas respectivas características, vantagens e desvantagens. 
QUADRO 5: Características dos Ensaios Não Destrutivos para ligações soldadas.

\begin{tabular}{|c|c|c|c|}
\hline $\begin{array}{l}\text { Ensaios Não } \\
\text { Destrutivos }\end{array}$ & Características & Vantagens & Desvantagens \\
\hline Inspeção Visual & $\begin{array}{l}\text { É o primeiro ensaio a ser } \\
\text { realizado. Todas as soldas devem } \\
\text { ser inspecionadas visualmente. } \\
\text { Possibilidade de identificação } \\
\text { rápida de descontinuidade e em } \\
\text { peças de geometria complexa. } \\
\text { Também é utilizado para verificar } \\
\text { a peça em si, como paralelismo } \\
\text { entre abas, linearidade e } \\
\text { planicidade. }\end{array}$ & $\begin{array}{c}\text { Simplicidade. } \\
\text { Ausência de equipamentos } \\
\text { sofisticados. } \\
\text { Custo reduzido }\end{array}$ & $\begin{array}{l}\text { Detecta apenas falhas } \\
\text { superficiais. } \\
\text { Necessidade de limpeza } \\
\text { prévia da superfície, } \\
\text { deixando-a isenta de } \\
\text { imperfeições que podem } \\
\text { mascarar o ensaio. }\end{array}$ \\
\hline $\begin{array}{c}\text { Líquido } \\
\text { Penetrante }\end{array}$ & $\begin{array}{l}\text { Descontinuidades superficiais em } \\
\text { materiais não porosos, metálicos } \\
\text { e não metálicos. } \\
\text { Materiais que podem ser } \\
\text { ensaiados: aços carbonos em } \\
\text { geral, aços inoxidáveis, alumínio, } \\
\text { bronze, titânio e vidros. }\end{array}$ & $\begin{array}{l}\text { Aplicável em materiais } \\
\text { magnéticos ou não magnéticos. } \\
\text { Fácil visualização e caracterização } \\
\text { da descontinuidade. } \\
\text { Aplicável em peças de geometrias } \\
\text { complexas. } \\
\text { Custo relativamente reduzido. }\end{array}$ & $\begin{array}{l}\text { Detecção exclusivamente } \\
\text { de descontinuidades } \\
\text { abertas à superfície. } \\
\text { Necessidade de limpeza } \\
\text { rigorosa antes da execução } \\
\text { do ensaio. Com as técnicas } \\
\text { convencionais não é } \\
\text { aplicável em materiais } \\
\text { porosos. }\end{array}$ \\
\hline $\begin{array}{l}\text { Partículas } \\
\text { Magnéticas }\end{array}$ & $\begin{array}{l}\text { Utilizado na detecção de } \\
\text { descontinuidades superficiais e } \\
\text { subsuperficiais em peças de } \\
\text { materiais ferromagnéticos. }\end{array}$ & $\begin{array}{l}\text { Simplicidade de aplicação, fácil } \\
\text { execução, rápido e de baixo custo } \\
\text { de operação. } \\
\text { Alta sensibilidade na detecção de } \\
\text { descontinuidades superficiais. } \\
\text { Detecção de descontinuidades } \\
\text { pouco subsuperficiais da peça. } \\
\text { Pode ser realizado em peças de } \\
\text { geometria complexa. }\end{array}$ & $\begin{array}{l}\text { Pode ser aplicado apenas } \\
\text { em materiais } \\
\text { ferromagnéticos. } \\
\text { Forma e orientação das } \\
\text { descontinuidades em } \\
\text { relação ao campo } \\
\text { magnético interferem } \\
\text { fortemente no resultado do } \\
\text { ensaio, sendo necessária, } \\
\text { em muitos casos, a } \\
\text { realização de mais de um } \\
\text { ensaio na mesma peça. }\end{array}$ \\
\hline $\begin{array}{c}\text { Ensaio } \\
\text { Radiográfico }\end{array}$ & $\begin{array}{l}\text { Pode ser aplicado durante as } \\
\text { etapas de fabricação ou em } \\
\text { serviços de manutenção. } \\
\text { Defeitos, como vazio e inclusões } \\
\text { que apresentam uma espessura } \\
\text { variável em todas as direções, } \\
\text { são facilmente detectados desde } \\
\text { que não sejam muito pequenos } \\
\text { em relação à espessura da peça. }\end{array}$ & $\begin{array}{l}\text { Registro permanente por meio de } \\
\text { filme ou imagem digitalizada de } \\
\text { fácil compreensão, facilitando a } \\
\text { situação de análise, laudo e } \\
\text { documentação, inclusive no } \\
\text { acompanhamento através de } \\
\text { auditagem. Inspeciona o interior } \\
\text { das peças. }\end{array}$ & $\begin{array}{c}\text { Difícil aplicação em peças } \\
\text { de geometria complexa. } \\
\text { Necessidade de acesso às } \\
\text { duas faces da peça. } \\
\text { Limitações na detecção de } \\
\text { descontinuidades planares } \\
\text { (trincas), mais graves em } \\
\text { relação a integridade } \\
\text { estrutural. Exige cuidados } \\
\text { de radioproteção que } \\
\text { incluem o isolamento da } \\
\text { área. Relativamente caro. }\end{array}$ \\
\hline Ultrassom & $\begin{array}{l}\text { Pode ser aplicado durante as } \\
\text { etapas de fabricação ou em } \\
\text { serviços de manutenção. } \\
\text { Defeitos, como vazio e inclusões } \\
\text { que apresentam uma espessura } \\
\text { variável em todas as direções. }\end{array}$ & $\begin{array}{l}\text { Elevado poder de penetração que } \\
\text { permite a detecção de } \\
\text { descontinuidades existentes no } \\
\text { interior das peças, numa vasta } \\
\text { gama de espessuras e materiais. } \\
\text { Sensibilidade elevada na } \\
\text { detecção de descontinuidades } \\
\text { muito pequenas. Precisão na } \\
\text { determinação da localização, } \\
\text { dimensão e forma das } \\
\text { descontinuidades. Não necessita } \\
\text { de acesso a ambos os lados da } \\
\text { superfície a ser ensaiada. }\end{array}$ & $\begin{array}{l}\text { Exige operadores muito } \\
\text { experientes. Difícil de } \\
\text { aplicar a peças de } \\
\text { geometria complexa e/ou } \\
\text { de espessuras muito } \\
\text { pequenas. O registro } \\
\text { permanente do teste não é } \\
\text { facilmente obtido. }\end{array}$ \\
\hline
\end{tabular}


As fotos da Figura 6, mostram o resultado de um ensaio realizado em uma peça que acabou de receber um furo, visualmente não apresenta nenhuma descontinuidade, porém após o ensaio de PM a trinca fica evidente.

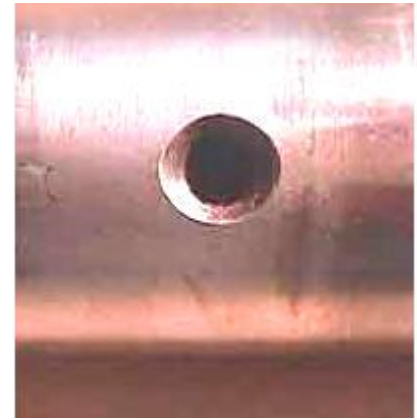

[a]

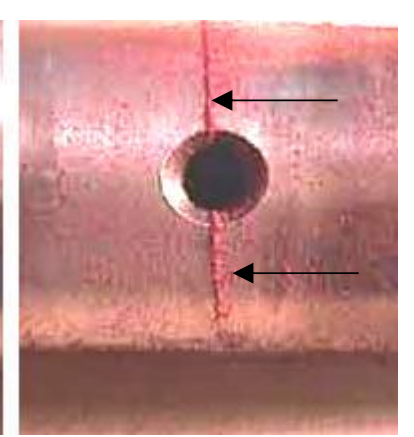

[b]
FIGURA 6: Foto da esquerda [a] mostrando a peça antes da inspeção por partículas e a foto da direita [b] mostrando a trinca originada do furo. FONTE: ANDREUCCI (2014).

\subsubsection{Inspeção Visual da Superfície Pintada}

Após a aplicação de cada demão de tinta, toda a superfície pintada deve ser inspecionada visualmente ou com auxílio de algum instrumento ótico para identificar eventual aparecimento de defeitos (NUNES e LOBO, 2014).

Atualmente, a experiência do inspetor é que, na maior parte das vezes, determina se o defeito é aceitável ou não. Contudo a Norma ASTM D 714 (2009) estabelece um método para qualificação do empolamento em função do tamanho e da distribuição das bolhas.

A Norma ASTM D 714 (2009) classifica as bolhas quanto ao tamanho e frequência que são apresentadas na superfície. Os tamanhos são classificas numa escala de 0 a 10, onde o número 10 significa ausência de bolhas. Bolhas $N^{\circ} 8$ representam 0 menor tamanho facilmente identificadas a olho nu. A frequência é qualificada em: D - Densa, MD - Médio-Densa, M - Média, F Pouco. A amostra é avaliada quanto ao aparecimento e evolução de bolhas e classifica-se conforme padrões visuais pré-determinados.

\subsubsection{Aferição das Espessuras das Películas de Tinta}

Esta é a mais tradicional das ações de controle de qualidade durante a aplicação de um esquema de pintura. A medição das espessuras das películas de tinta é muito importante e deve ser realizada para cada demão de tinta em dois estágios, primeiramente é medida a espessura da película úmida e posteriormente com a película seca. A medição da espessura de película úmida normalmente é feita pelo pessoal da execução e visa o controle da aplicação, evitando descontinuidades ou consumo exagerado da tinta. Esta medição é realizada com auxílio de instrumento do tipo calibre comparador (NUNES e LOBO, 2014).

Para a espessura da película seca, são utilizados instrumentos do tipo elcometer, microtes ou eletrônicos e todos têm funcionamento baseados no princípio de emissão de campo magnético. Na Figura 7, são apresentadas fotos realizadas pelo autor em fábrica de estruturas metálicas, onde mostram o ensaio de aferição de espessura de película de tinta.

A inspeção das películas secas de tinta consiste em avaliar algum tipo de deficiência na película de tinta, isso por estarem sujeitas a falhas que podem afetar a real necessidade do desempenho das tintas. As falhas podem ser pontuais ou generalizadas, que podem ter como principal causador itens já relacionados com controles de processos, condições ambientais e aplicabilidade dos produtos.

Esse controle tem como objetivo evidenciar a camada de tinta seca especificada pelo boletim técnico da tinta, pois, a tinta serve como uma barreira que promove a proteção anticorrosiva no substrato.

Segundo a norma Petrobras N-13 revisão $K$, a medição da espessura deve ser afetada após decorrido o tempo de secagem para repintura de cada demão e deve ser realizado um número de medições correspondente, em valor absoluto, a $10 \%$ da área total pintada.
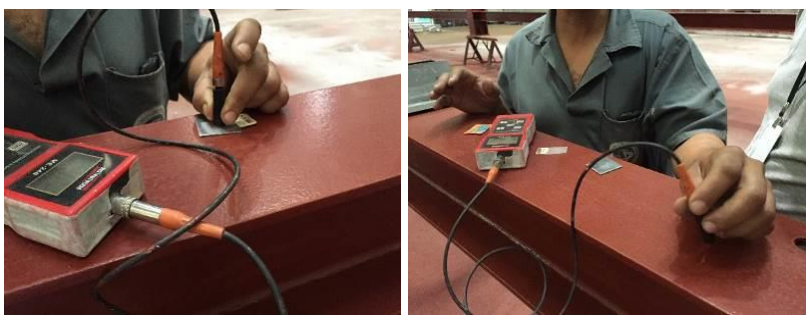

FIGURA 7: Medição da espessura de película de tinta. FONTE: Autoria própria. 


\subsubsection{Determinação de Descontinuidades}

$O$ teste de descontinuidade normalmente deve ser realizado após a conclusão da aplicação de esquemas de pintura de alto desempenho no que diz respeito a corrosão. Quando efetuado, deve abranger toda a superfície pintada. É especialmente recomendado para esquemas de pintura que irão trabalhar em imersão permanente e em atmosferas muito úmidas e agressivas (NUNES e LOBO, 2014).

Existem dois aparelhos diferentes para avaliar eventuais descontinuidades no esquema de pintura. Ambos têm como princípio avaliar a capacidade de uma corrente elétrica de atravessar a película de tinta. $\mathrm{O}$ aparelho por via úmida é de baixa voltagem e só identifica falhas passantes, ou seja, que atravessam toda a espessura do esquema de pintura. Uma esponja de poliuretano, na extremidade do cabo, encharcada em água salgada, cria condições ideais para a corrente elétrica atravessar a película de tinta na região da falha e indicá-las por meio de um sinal luminoso ou sonoro. Já o aparelho por via seca é de alta voltagem (até 30.000 volts). A grande vantagem desse aparelho é o poder de identificar qualquer tipo de falha, passante ou não, inclusive regiões com baixas espessuras. A desvantagem é que é inadequado para esquemas de baixas espessuras, pois por menor que seja a voltagem regulada, a corrente pode perfurar a película de tinta.

Desse modo, ao aparelho de via úmida é utilizado para avaliar descontinuidades em esquemas de pintura cuja espessura total não ultrapasse $100 \mu \mathrm{m}$, e o de via seca, para os demais casos (NUNES e LOBO, 2014).

\section{RESULTADOS E DISCUSSÕES}

Neste trabalho apresentaram-se os critérios mínimos que se deve utilizar no controle de qualidade no projeto, fabricação e montagem de estruturas metálicas, além das principais manifestações patológicas e suas origens, motivadas por falhas no controle de qualidade em alguma etapa da construção. Manifestações essas, corroboradas em visitas técnicas realizadas obras de estruturas metálicas.
Com isso, se sugere um procedimento para elaboração do projeto, fabricação e montagem de estruturas metálicas, com controle de qualidade da gestão das principais fases do processo e utilizando os ensaios não destrutivos mais comuns no Brasil.

Um aspecto importantíssimo a ser definido a respeito dos ensaios não destrutivos é a amostragem, ou seja, a extensão de solda que será objeto dos ensaios. Devem também estar definidos, após os resultados dos ensaios, quais e quantos defeitos serão aceitáveis, e em qual extensão. Normas mais completas como as da Petrobras definem a amostragem de solda que devem sofrer inspeção para cada tipo de ensaio, no entanto, essa preposição é direcionada para as necessidades especificas da Petrobras, como plataformas petrolíferas, navios-sonda, estruturas metálicas industriais e com elevada agressividade ambiental.

As estruturas metálicas, como qualquer outro tipo de estrutura ou outro tipo de fabricação, requerem padrões que permitam ter uma estrutura de qualidade e durabilidade e se comportem de acordo com o que foi calculado, sem exageros ou negligências.

Propõe-se neste trabalho diferentes níveis de controle de qualidade nas ligações soldadas, com base nos padrões de construção indicados por Bellei (2010), para as tolerâncias de fabricação e na extensão e seleção de ensaios não destrutivos recomendados pela Norma N-293 REV H da Petrobras (2013).

Bellei (2010), estabelece padrões como sendo rigoroso, normal e comercial. Contudo, adaptou-se esses padrões, discriminando mais tipos de estruturas em cada padrão e alterando o nome do padrão comercial para brando. Portanto, a seguir estão os três padrões propostos:

Padrão I (Rigoroso) - Para estruturas que requerem maior rigor dimensional, como vigas e colunas de edifícios industriais, edifícios com mais de quatro pavimentos, vigas de rolamento, estruturas-suporte de grandes cargas, pontes ferroviárias, etc.

Padrão II (Normal) - Para estruturas convencionais, como galpões industriais, exceto vigas de rolamento, vigas e colunas de edifícios de 
pequeno porte, pórticos, mezaninos, steel-decks, etc.

Padrão III (Brando) - Para estruturas secundárias e complementares, como estacas, postes, escadas, corrimãos, plataformas de acesso, etc.

As estruturas podem estar enquadradas em um padrão, mas algumas de suas partes podem estar em outro. O objetivo é que com tempo e sugestões de outros fabricantes se tenha uma norma nacional controle de qualidade na fabricação e montagem de estruturas metálicas para diversos tipos de utilização.

Por fim, se elaborou um plano de inspeção em ligações soldas, representado pelo Quadro 6, indicando quais inspeções devem ser feitas e a sua amostragem, baseado nos diferentes padrões estabelecidos de estruturas metálicas.

As siglas utilizadas significam:

a) JASA: junta de ângulo com solda de filete.

b) JTPT: junta de topo com penetração total. c) JAPT: junta de ângulo com penetração total.

d) ER: ensaio radiográfico.

e) US: ensaio por ultrassom.

f) PM: ensaio por partículas magnéticas.

g) LP: ensaio por líquido penetrante.

As soldas dos componentes de nível de inspeção III devem ser totalmente inspecionadas visualmente segundo a AWS D1.1/D1.1M (2010). Os ensaios de PM e LP podem ser tratados como equivalentes, com preferência para a utilização do PM. Portanto, sempre que previsto o ensaio PM mas não for possível realizar, poderá ser usar do LP, sendo o inverso também válido.

A extensão dos ensaios indicados no Quadro 3 para os níveis de Inspeção I e II são aplicáveis para cada solda. Todas as soldas dos componentes de nível de inspeção I, II e III devem ser inspecionadas por ensaio visual.

A extensão dos ensaios indicados neste Quadro para os níveis de Inspeção I e II são aplicáveis para cada solda (Norma N-293 REV H da PETROBRAS, 2013).

\begin{tabular}{|c|c|c|c|c|c|}
\hline \multirow{2}{*}{$\begin{array}{c}\text { Padrão } \\
\text { (Nível de Inspeção) }\end{array}$} & \multirow{2}{*}{ Tipo de solda } & \multicolumn{4}{|c|}{ Extensão dos ensaios (\%) } \\
\hline & & ER & US & PM ou LP & Visual \\
\hline \multirow{3}{*}{ I } & JASA & - & - & 100 & 100 \\
\hline & JTPT & - & 50 & 100 & 100 \\
\hline & JAPT & - & 100 & 100 & 100 \\
\hline \multirow{3}{*}{ II } & JASA & - & - & 50 & 100 \\
\hline & JTPT & - & 50 & 50 & 100 \\
\hline & JAPT & - & 50 & 50 & 100 \\
\hline
\end{tabular}




\section{CONSIDERAÇÕES FINAIS}

Diante do exposto, se pode constatar que a proposta apresentada é um fomento à discussão sobre critérios para o controle de qualidade de estruturas metálicas, desde as mais complexas, até as mais comuns. As últimas inclusive são as que constituem a grande maioria das construções metálicas no Brasil e são por esse motivo que se devem aprofundar os estudos nessa matéria.

Normas e padrões para estruturas metálicas de pequeno e médio porte que garantam a qualidade e a vida útil do projeto, ainda não são realidade no Brasil. A construção em estrutura metálica é um sistema que possui características próprias tanto na concepção quanto no desenvolvimento. Isso significa que desde a etapa do projeto até a fase final da montagem, devem existir cuidados que precisam ser observados para não cometer erros construtivos, facilmente evitáveis por meio do planejamento e fiscalização eficientes.

Desta forma, pode-se deduzir é possível demonstrar que o controle de qualidade se faz uma ferramenta essencial para garantir a vida útil das estruturas, uma vez que ao longo do processo construtivo, permite garantir uma padronização nas estruturas.

\section{AGRADECIMENTOS}

Ao meu orientador Alex Sander Clemente de Souza, por ter colaborado na execução da pesquisa e proporcionado auxílio técnico. A Universidade Federal de São Carlos - UFSCar e, por fim, as empresas que participaram deste trabalho cedendo informações para o desenvolvimento do mesmo.

\section{REFERÊNCIAS BIBLIOGRÁFICAS}

AMERICAN WELDING SOCIETY - AWS D1-1 - "Structural Welding Code" -Steel. 22 ed. 2010. Miami- EUA.

ANDREUCCI, R. Ensaio por Partículas Magnéticas. Associação brasileira de ensaios não destrutivos e inspeção (ABENDI). 68 p. São Paulo. Out.2014.
ASSOCIAÇÃO BRASILEIRA DE ENSAIOS NÃO DESTRUTIVOS E INSPEÇÃO (ABENDI). Guia de END e Inspeção. São Paulo, 2015.

ASTM 714-02 (Reapproved 2009), "Standard Test Method for Evaluating Degree of Blistering of Paints" (West Conshohocken, PA: ASTM).

BAUERMANN, M. Investigação sobre o processo de projeto em edifícios de andares múltiplos de aço. 2002. 269 p. Dissertação (Mestrado em Construção Metálica) Escola de Minas, Universidade Federal de Ouro Preto, Ouro Preto, 2002.

BELLEI, I. H. Edifícios industriais em aço- Projeto e cálculo. 6 ed. São Paulo: Pini, 2010. 502 p.

BUREAU SECURITAS. Étude statistique de $\mathbf{1 0 0 0 0}$ dossiers de sinistres. Annales de L'Institut Technique du Bâtiment et des Travaux Publics, no378, Paris, France, 1979.

COSTA, F. G. Manutenção das estruturas metálicas com utilização dos ensaios não destrutivos. Construmetal 2012. São Paulo, 2012.

HENRIQUES, F. M. A. Noção de Qualidade em Edifícios. Comunicação ao Congresso Nacional da Construção. Lisboa, 2001.

NETTO, E. P. G. Estudo de caso da implantação do controle de qualidade na fabricação e soldagem de estruturas metálicas em aço carbono. 47 p. Monografia (Curso Técnico em Mecânica). São José do Rio Preto, 2010.

NUNES, L. P.; LOBO, A. C. O. Pintura industrial na proteção anticorrosiva. 5 ed. Rio de Janeiro: Interciência, 2014.

PETROBRAS. N- 13 REV.K. Requisitos Técnicos para Serviços de Pintura. 28 f. Dez.2012.

PETROBRAS. N- 1594 REV.F. Ensaio não - destrutivo Ultrassom. 22 f. dez.2004.

PETROBRAS. N- 1595 REV. G. Ensaio não - destrutivo Radiografia. 19 f. Nov.2012.

PETROBRAS. N- 1596 REV H. Ensaio não - destrutivo Líquido penetrante. Set. 2013.

PETROBRAS. N- 1597 REV. D. Ensaio não - destrutivo visual. 6 f. ago. 1996.

PETROBRAS. N- 293 REV. H. Fabricação e Montagem de Estruturas Metálicas, 34 f. dez.2013.

PETROBRAS. N-1598 REV.E. Ensaio não - destrutivopartículas magnéticas. 17 f. nov.2003.

PRAVIA, Z. M. C.; BETINELLI, E. A. Falhas em estruturas metálicas: Conceitos e estudos de caso. Curso de 
Engenharia Civil da FEAR -UPF. Disponível em:<Portal metálica>. Acesso em 22 abr. 2016.

RAAD JUNIOR, A.A. Diretrizes para fabricação e montagem das estruturas metálicas. 243 f. Dissertação (Mestrado em Engenharia Civil) - Ouro Preto, 1999.

SANTOS, J. F. O. Ensaio Não Destrutivos: guia do formando. Portugal, Lisboa: Instituto do Emprego e Formação Profissional, 1999. 154p. 